\title{
Correlation of Chemerin with some Immunological Parameters in Type II Diabetes Mellitus Patients on Hemodialysis in Ramadi General Hospital
}

\author{
Salahaldin M. Fahad ${ }^{1, *}$, Rashied M. Rashied ${ }^{2}$, and Waleed N. Jaffal ${ }^{3}$ \\ ${ }^{1}$ Department of Biology, College of Sciences, University Of Anbar. Iraq. ${ }^{2}$ Department of Biotechnology, College of Sciences, University Of \\ Anbar. Iraq. ${ }^{3}$ Department of Surgery, College of Medicine, University Of Anbar. Iraq.
}

Received: July 7, 2020; Revised: November 13, 2020; Accepted: December , 2020

\begin{abstract}
Diseases of kidney are among the most important causes of death in many countries. The major causes of chronic kidney disease include diabetes mellitus and chronic hypertension. This study was designed to evaluate some hematological and inflammation aspects in 95 patients, divided into (35) hemodialysis patients with diabetes, (35) hemodialysis patients without diabetes and (25) diabetes patients, and who attended at Ramadi General Hospital, in addition to (25) samples as control subject. Chemerin, Interleukin-18 (IL-18) and high sensitive C-reactive protein (hs-CRP) were established by ELISA. The results showed serum chemerin, interleukin-18 and hs-CRP were significantly higher in HD patients with diabetes $(230.13 \pm 78.26 \mathrm{ng} / \mathrm{ml}$ at $\mathrm{P}=0.034,677.23 \pm 99.14 \mathrm{pg} / \mathrm{mL}$ at $\mathrm{P}=0.026$, and $15.77 \pm 2 \mathrm{mg} / \mathrm{L}$ at $\mathrm{P}=0.048$ ), respectively compared with control $(110 \pm 20.42 \mathrm{ng} / \mathrm{ml}, 143.68 \pm 35.78 \mathrm{pg} / \mathrm{mL}$, and $4.64 \pm 1.27 \mathrm{mg} / \mathrm{L})$, respectively. The results showed the significant and positive correlations between chemerin and hs-CRP or chemerin and IL-18 ( $\mathrm{r}=0.149$ at $\mathrm{P}=0.004$ or $\mathrm{r}=0.123$ at $\mathrm{P}=0.0325$ in control), $(\mathrm{r}=0.165$ at $\mathrm{P}=0.007$ or $\mathrm{r}=0.190$ at $\mathrm{P}=0.024$ in diabetic patients), $(\mathrm{r}=0.237$ at $\mathrm{P}=0.0036$ or $\mathrm{r}=0.263$ at $\mathrm{P}=0.038$ in $\mathrm{HD}$ patients with diabetic) and $(\mathrm{r}=0.0 .235$ at $\mathrm{P}=0.0081$ or $\mathrm{r}=0.248$ at $\mathrm{P}=0.041$ in HD patients without diabetic) respectively. The mean of hemoglobin (Hb), Packed Cells Volume (PCV), Red Blood cells (RBC), White Blood Cells (WBC) and Lymphocytes were significantly decreased in HD patients without diabetes (8.55 $\pm 0.63 \mathrm{~g} / \mathrm{L}$ (at $\mathrm{p}=0.0423)$, $27.63 \pm 1.31 \%$ (at $\mathrm{p}=0.028$ ), $3.12 \pm 0.56 \times 10^{12} \backslash \mathrm{L}$ (at $\mathrm{p}=0.035$ ), $6.7 \pm 0.53 \times 10^{9} / \mathrm{L}$ (at $\mathrm{p}=0.021$ ) and $30.23 \pm 5.84 \%($ at $\mathrm{p}=0.046$ ), respectively compared with control. The mean of Monocytes\% (17.23 $\pm 7.28 \%$ at $\mathrm{p}=0.031)$ and Granulocyte\% $(59.31 \pm 9.45 \%$ at $\mathrm{p}=0.042$ ) were significantly higher in HD patients with diabetes, while mean of Mononocytes\% was significant lower in diabetic patients. This study suggests a significant role of chemerin, hs-CRP and IL-18 in the pathogenesis and progression of diabetic complications, and we can use these parameters for predicting the progression of diabetic nephropathy in the early stages of CKD.
\end{abstract}

Keywords: Chronic kidney disease (CKD), Chemerin, Type II Diabetes mellitus (T2DM), Hemodialysis (HD), Interleukin-18.

\section{Introduction}

Chronic kidney disease is a progressive loss of kidney function over a period of months or years through five stages. Therefore, CKD is a major global public health problem (George et al., 2015). The single most common of CKD is diabetic nephropathy (DN), which occurs as a result of microangiopathy caused by diabetes, where approximately one-third of all diabetic patients are affected by DN (Franz et al., 2012). In addition, renal involvement is a major cause of morbidity and mortality in the diabetic population (Donate-Correa et al., 2015). Persistent inflammation is a risk factor of CKD progress, thereby inflammation reduction is very significant in the treatment of kidney disease (Kurts et al., 2013). Interleukin-18 (IL-18) is a pro-inflammatory protein that acts as an immunoregulatory agent involved in the reactions of both innate and acquired immunity (Kraydaschenko et al., 2016). Recently, IL-18 has been suggested to play a crucial role in the initiation, development, and progression of DN inT2DM patients (Abid Hammed, 2019). Accordingly, plasma IL-18 may reflect insulin-resistance not only in patients with established T2DM, but also in non-diabetic controls(Fischer et al., 2005). Among inflammatory biomarkers, the best evidence to date supports the use of hs-CRP as an independent predictor of increased cardiovascular disease (CVD) risk in diabetic and nondiabetic patients(Pfützner et al., 2007). HsCRP is a wellknown marker of systemic inflammation and a most frequently used inflammation marker(Ali et al., 2019). These characteristics make hsCRP a reliable marker of inflammation(Thaha et al., 2018). In CKD, IL-18 has been proposed to be a marker for early detection and outcome prediction in patients with acute myocardial infraction, and nephropathy(Chang et al., 2015). Adipose tissue produces a variety of proteins called adipokines, one of which is chemerin, which modulates the function of innate immune cells and may be a potential candidate in the pathogenesis of cardiovascular complications (Salama et al., 2016). Chemerin positively correlated with inflammatory markers

\footnotetext{
*Corresponding author e-mail: salahalden615@gmail.com.
} 
such as hs-CRP(Blaszak et al., 2015). Interestingly, it has been previously reported that kidney function is inversely related to circulating chemerin in HD patients, chemerin features anti-microbial as well as chemotactic properties, plays a regulatory role for immune response including regulation of specific immune cell migration, and antiinflammatory effects on macrophages (Leiherer et al., 2016; Haddad et al., 2018). Anemia is a common feature in patients with CKD and is mainly attributable to the relative decrease in erythropoietin (EPO) production by the kidneys(Vanholder et al., 2016). Anemia is defined as $\mathrm{Hb}$ level lower than (12)g/dL in humans according to WHO (Latiweshob et al, 2017). Stanifer et al., (2014) reported that mean of RBCs, $\mathrm{Hb}$, and $\mathrm{PCV}$ are significantly lowered in CKD patients, which occurs earlier in these patients and tends to be of greater severity by CKD stages. Elevated total WBC and granulocyte counts are correlated with the raised progression of CKD (Kuo et al., 2018). Therefore, this study aimed to determine the association between immunological markers such as chemerin, IL-18, and hsCRP and diabetic nephropathy diagnosis in hemodialysis patients.

\section{2. Materials and Methods}

\subsection{Time and Location of collection}

The Specimens collection were started from April, 2019 till the end of June 2019. HD patients with diabetes and HD patients without diabetes samples were collected from the Industrial Renal department and T2DM patients from the Diabetes Center for Treatment at Ramadi General Hospital.

\subsection{Study design}

The study is designed on 95 patients at age rang (3070) years. The patients in this study included (35) hemodialytic patients with diabetes and (35) hemodialytic patients without diabetes and (25) T2DM patients without any other complications. The diagnosis was performed by specialist doctors. And (25) samples as control group were included in the study. The controls were selected among subjects who were healthy in terms of non-diabetic, nonhypertensive, no other endocrine disorders at the time of sampling.

\subsection{Blood Samples Collection}

Before the collection of samples, all patients provided written informed consent prior to participation in this study, which was approved by institutional ethics committees (university Of Anbar $\backslash$ ethical approval committee). From each patient and control, $5 \mathrm{ml}$ of blood was obtained. The blood samples were divided into two aliquots; $2 \mathrm{ml}$ was dispensed in tube containing ethylene diamine tetracetic acid (EDTA). This blood was used for CBC estimation such as white blood cells (WBC), WBC differentiation, red blood cells (RBC), hemoglobin (Hb) and packed cell volume (PCV). While $3 \mathrm{ml}$ was dispensed in a gel plain tube to collect serum, the serum was used to estimate the Chemreine, interleukin-18, and Hs-CRP by using ELISA technique.

\subsection{Anthropometric Measurements}

Patients and controls are characterized in terms of age, gender, smoking and body mass index (BMI). The BMI is calculated by dividing weight (kilogram)/ the squared height (meter), BMI= Kg/m2 (Abid Hammed, 2019).

\section{5. laboratory investigation}

Concentrations of serum chemrein was estimated by commercially available chemerin ELISA assays kit provided from Elabscience Company / U.S.A. The IL-18 level was estimated by the direct ELISA kit method provided from Elabscience Company / U.S.A. The concentrations of serum HsCRP was measured by the ELISA direct kit method which provided from Shanghai company / China. All ELISA procedures were carried out according to the manufacturer's instructions.

\subsection{Determination of hematological parameters}

Hematological parameters in whole blood of all study groups are determined by using an automated hematology analyzers XT 2000i (from sysmex, Japan).

\subsection{Statistical Methods:}

The data were translated into a computerized database structure, and the statistical analyses were carried out using SPSS version 25. One way ANOVA test was used to find means and standard deviation (SD) for all variables of the study. The difference of significances in proportions was analyzed by LSD test. The correlations between variables was confirmed by Pearson correlation analysis. P-value less than 0.05 was considered to be significant.

\section{Results}

\subsection{Characteristics of controls and patients:}

These results showed no significant difference at level $(p \leq 0.05)$ in mean of age, smoking, gender and BMI among patients and healthy control, as shown in table (1).

Table 1. Characteristics of controls and patients:

\begin{tabular}{llllll}
\hline Factor & Control & T2DM & $\begin{array}{l}\text { HD patients } \\
\text { with } \\
\text { diabetes }\end{array}$ & $\begin{array}{l}\text { HD patients } \\
\text { without } \\
\text { diabetes }\end{array}$ & P \\
\hline Age(Y) & $52.6 \pm 6.01$ & $54.12 \pm 7.83$ & $55.94 \pm 11.2$ & $53 \pm 12.47$ & $0.065^{\mathrm{NS}}$ \\
$\begin{array}{l}\text { Gender } \\
\text { (M/F) }\end{array}$ & $12 \mathrm{M} / 13 \mathrm{~F}$ & $12 \mathrm{M} / 13 \mathrm{~F}$ & $16 \mathrm{M} / 19 \mathrm{~F}$ & $15 \mathrm{M} 20 \mathrm{~F}$ & $0.507^{\mathrm{NS}}$ \\
$\begin{array}{l}\text { Smoking } \\
\text { (S/no S) }\end{array}$ & $10 / 15$ & $14 / 11$ & $17 / 18$ & $22 / 13$ & $0.113^{\mathrm{NS}}$ \\
BMI & $24.61 \pm 0.35$ & $28.97 \pm 0.4$ & $28.71 \pm 0.54$ & $27.03 \pm 0.62$ & $0.777^{\mathrm{NS}}$ \\
\hline
\end{tabular}

Results were expressed as mean \pm SD, ANOVA test was used for the purpose of comparison between the four groups. * NS: Mean non-significant differences at $\mathrm{P} \leq 0.05$.

$\mathbf{H D}=$ hemodialysis, $\mathbf{B M I}=$ body mass index, $\mathbf{M}=$ Male, $\mathbf{F}=$ female, $\mathbf{S}=$ Smokers, no $\mathbf{S}=$ no smokers, $\mathbf{T 2 D M}=$ Type II diabetes mellitus.

\subsection{Determination of Chemrein between the four study groups}

As shown in the table (2), the mean of serum Chemerin was significantly higher in HD patients with diabetes (230.13 \pm 78.26$) \mathrm{ng} / \mathrm{ml}$, followed by HD patients without diabetes (221.90 \pm 65.17$) \mathrm{ng} / \mathrm{ml}$ compared with control $(110 \pm 20.42) \mathrm{ng} / \mathrm{ml}$. Also, mean of serum chemerin significant increased in diabetic patients (212.29 \pm 70.88$) \mathrm{ng} / \mathrm{ml}$ when compared with control. 
Table 2. The difference in chemerin level between the four study groups:

\begin{tabular}{|c|c|c|c|}
\hline \multicolumn{4}{|c|}{ Chemerin (30-190) ng/ml } \\
\hline Groups & $\mathrm{N}$ & Mean \pm SD & Range \\
\hline Control & 25 & $110 \pm 20.42 a$ & $(95-175)$ \\
\hline Diabetes & 25 & $212.29 \pm 70.88 b$ & $(142-275)$ \\
\hline $\begin{array}{l}\text { HD patients with } \\
\text { diabetes }\end{array}$ & 35 & $230.13 \pm 78.26 \mathrm{c}$ & $(172-297)$ \\
\hline $\begin{array}{l}\text { HD patients without } \\
\text { diabetes }\end{array}$ & 35 & $221.90 \pm 65.17 d$ & $(152-273)$ \\
\hline Total & 120 & $183.66 \pm 21.68$ & $(95-297)$ \\
\hline
\end{tabular}

*Different Letters (a, b, c, d): Mean significant difference at $\mathrm{P}$ $=0.034$.

SD= Stander Deviation.

3.3. Human IL-18(Interleukin 18) level between the four study groups

As demonstrated in table (3), the IL-18 level was significantly higher in HD patients with diabetes (677.23 \pm 99.14$) \mathrm{pg} / \mathrm{mL}$ followed by HD patients without diabetes $(589 \pm 44.77) \mathrm{pg} / \mathrm{mL}$ compared with control group(143.68 \pm 35.78$) \mathrm{pg} / \mathrm{mL}$, also IL-18 level was significantly increased in diabetic patients (245.18 \pm 87.45$)$ $\mathrm{pg} / \mathrm{mL}$ when compared with control group.

Table 3. The difference in IL-18 level between the four study groups:

\begin{tabular}{llll}
\hline IL-18 $(20-800) \mathrm{pg} / \mathrm{mL}$ & & & \\
\hline Groups & $\mathrm{N}$ & Mean \pm SD & Range \\
\hline Control & 25 & $143.68 \pm 35.78^{\mathrm{a}}$ & $(110-178)$ \\
Diabetes & 25 & $245.18 \pm 87.45^{\mathrm{b}}$ & $(168-332)$ \\
HD patients with diabetes & 35 & $677.23 \pm 99.14^{\mathrm{c}}$ & $(578-776)$ \\
HD patients without & 35 & $589 \pm 44.77^{\mathrm{d}}$ & $(545-633)$ \\
diabetes & & & \\
Total & 120 & $413.12 \pm 76.58$ & $(312-524)$ \\
\hline
\end{tabular}

*Different Letters (a, b, c, d): Mean significant difference at P $=0.026$.

SD= Stander Deviation, IL-18= Interleukin 18.

\subsection{Human high sensitivity C-Reactive Protein (hs- CRP) level in four study groups}

As shown in the table (4), the mean of hs-CRP was significantly higher in HD patients with diabetes $(15.77 \pm 2) \mathrm{mg} / \mathrm{L}$ followed by HD patients without diabetes

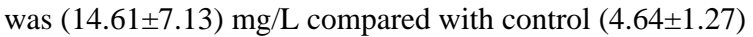
$\mathrm{mg} / \mathrm{L}$, also mean of serum hs-CRP was significant increase diabetic patients $(8.06 \pm 2.28) \mathrm{mg} / \mathrm{L}$ when compared with control.
Table (4): The difference in hsCRP level between the four study groups:

\begin{tabular}{lccl}
\hline Hs-CRP (0.05-12)mg/L & & & \\
\hline Groups & N & Mean \pm SD & Range \\
\hline $\begin{array}{l}\text { Control } \\
\text { Diabetes }\end{array}$ & 25 & $4.64 \pm 1.27^{\mathrm{a}}$ & $(3.44-5.8)$ \\
$\begin{array}{l}\text { HD patients with } \\
\text { diabetes }\end{array}$ & 25 & $8.06 \pm 2.28^{\mathrm{b}}$ & $(5.78-10.3$ \\
$\begin{array}{l}\text { HD patients without } \\
\text { diabetes }\end{array}$ & 35 & $15.77 \pm 2^{\mathrm{c}}$ & $(13.7-17.7)$ \\
Total & 120 & $10.42 \pm 4.40$ & $(4.4-20.6)$ \\
\hline
\end{tabular}

*Different Letters (a, b, c): Mean significant difference at $\mathrm{P}$ $=0.048$.

$\mathbf{S D}=$ Stander Deviation, $\mathbf{h s}-\mathbf{C R P}=$ high sensitivity C-Reactive Protein.

\subsection{Correlation between Chemerin and hs-CRP or} Chemerin and IL-18 between the four study groups.

As shown in Figures (1) and (2), there were significant and positive correlations between chemerin and hs-CRP (r $=0.149, \mathrm{P}=0.004$; Figure A1) or chemerin and IL-18 $(\mathrm{r}=0.123, \mathrm{P}=0.0325$; Figure $\mathrm{B} 1)$ in control group. The correlations between chemerin and hs-CRP were $(r=0.165$, $\mathrm{P}=0.007$; Figure A2) and ( $\mathrm{r}=0.237, \mathrm{P}=0.0036$; Figure $\mathrm{A} 3$ ) or chemerin and IL-18 were $(r=0.190, P=0.024$; Figure B2) and ( $r=0.263, P=0.038$; Figure B3) in diabetic patients group and HD patients with diabetic group respectively. Figure A4 indicates the correlation of chemerin with hsCRP ( $\mathrm{r}=0.0 .235, \mathrm{P}=0.0081)$ and chemerin with IL-18 $(r=0.248, P=0.041$; Figure B4) in HD patients without diabetic group.

\subsection{Determination of $\mathrm{Hb}, \mathrm{PCV}$ and $\mathrm{RBC}$ in the four study groups.}

The result indicates the significant difference in mean of $\mathrm{Hb}, \mathrm{PCV}$, and RBC in groups of the study. The levels of $\mathrm{Hb}, \mathrm{PCV}$, and RBC were significantly decreased in HD patients with diabetes group and HD patients without diabetes group $(8.76 \pm 0.78$ and $8.55 \pm 0.63) \mathrm{g} / \mathrm{L}$, (28.29 \pm 1.62 and $27.63 \pm 1.31) \%$, and (3.27 \pm 0.40 and $3.12 \pm 0.56) \times 1012 \backslash \mathrm{L}$ respectively, compared with control group $\quad(13.32 \pm 1.70) \mathrm{g} / \mathrm{L}, \quad(41.88 \pm 2.90) \% \quad$ and $(4.81 \pm 0.60) * 10^{12} \backslash \mathrm{L}$, while $\mathrm{Hb}, \mathrm{PCV}$, and RBC showed non-significant difference in diabetic patients group: $(13.1 \pm 1.41) \mathrm{g} / \mathrm{L},(41.78 \pm 1.33) \%$, and $(4.651 \pm 0.70) \times 10^{12}$ $\mathrm{L}$ compared with control, as shown in the table (5). 

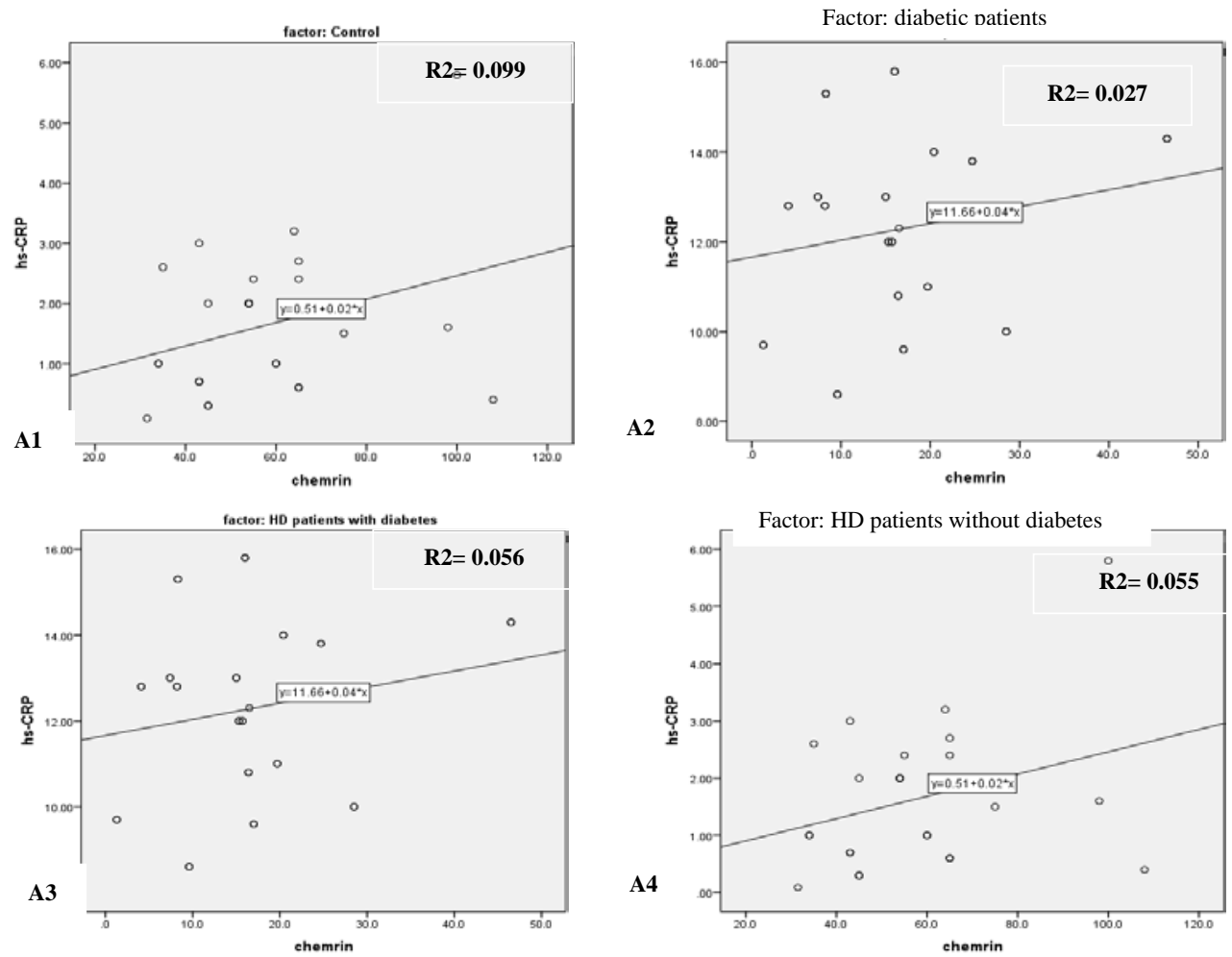

Figure1. Correlation determine between serum Chemerin and high sensitivity C-Reactive Protein (hs-CRP):

Figure A1: In control at $\mathrm{P}=0.004$. Figure A2: In diabetic patients at $\mathrm{P}=0.007$. Figure A3: HD patients with diabetes at $\mathrm{P}=0.0036$.Figure $\mathrm{A} 4$ : HD patients without diabetes at $\mathrm{P}=0.0081$.
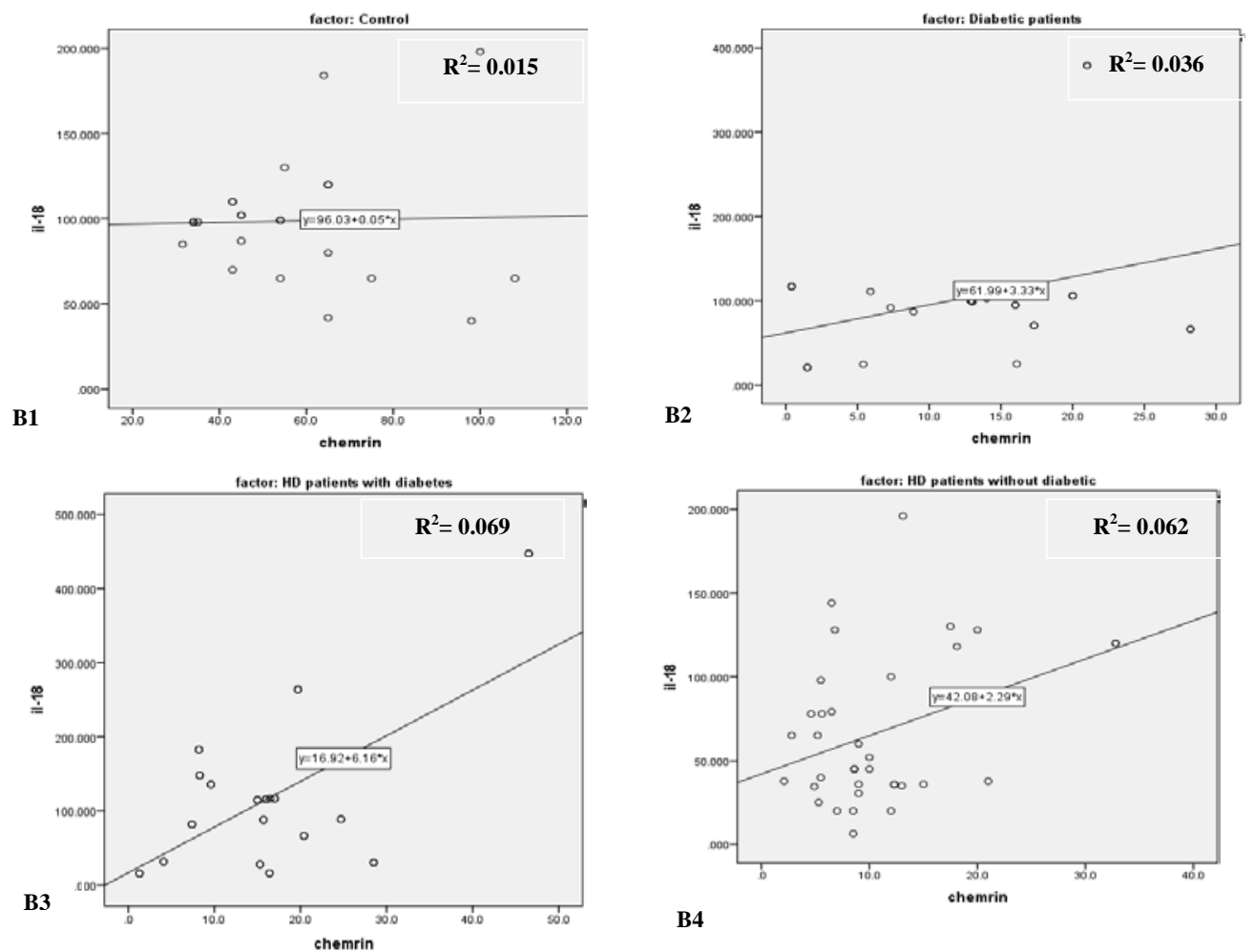

Figure 2. Correlation between serum Chemerin and Interleukin-18 (IL-18): Figure B1: In control at $P=0.0325$.Figure $\mathrm{B} 2$ : In diabetic patients at $\mathrm{P}=0.024$.Figure $\mathrm{B} 3$ : In HD patients with diabetes at $\mathrm{P}=0.038$. Figure $\mathrm{B} 4$ : In HD patients without diabetes at $\mathrm{P}=0.041$. 
Table (5): The difference in Hb, PCV and RBC in the four study groups.

\begin{tabular}{|c|c|c|c|c|}
\hline Groups & N. & $\begin{array}{l}\text { Mean士SD } \\
\text { Hb } \\
(12-16) g \backslash L\end{array}$ & $\begin{array}{l}\text { Mean士SD } \\
\text { PCV \% } \\
(36-50) \%\end{array}$ & $\begin{array}{l}\text { Mean } \pm S D \\
\text { RBCs } \\
(3.8-5.5) \\
\times 10^{12} \backslash \mathrm{L}\end{array}$ \\
\hline Control & 25 & $13.32 \pm 1.70^{\mathrm{a}}$ & $41.88 \pm 2.90^{\mathrm{a}}$ & $4.81 \pm 0.60^{\mathrm{a}}$ \\
\hline Diabetes & 25 & $13.1 \pm 1.41^{\mathrm{a}}$ & $41.78 \pm 1.33^{\mathrm{a}}$ & $4.651 \pm 0.70^{a}$ \\
\hline $\begin{array}{l}\text { HD patients with } \\
\text { diabetes }\end{array}$ & 35 & $8.76 \pm 0.78^{b}$ & $28.29 \pm 1.62^{b}$ & $3.27 \pm 0.40^{\mathrm{b}}$ \\
\hline $\begin{array}{l}\text { HD patients } \\
\text { without diabetes }\end{array}$ & 35 & $8.55 \pm 0.63^{b}$ & $27.63 \pm 1.31^{c}$ & $3.12 \pm 0.56^{\mathrm{b}}$ \\
\hline Total & 120 & $10.76 \pm 2.40$ & $34.43 \pm 7.69$ & $3.55 \pm 0.86$ \\
\hline P Value & & 0.0423 & 0.028 & 0.035 \\
\hline
\end{tabular}

*Different Letters (a, b, c): Mean significant difference at $\mathrm{P}$ $\leq 0.05$.

$\mathbf{S D}=$ Stander Deviation, $\mathbf{H b}=$ Hemoglobin, $\mathbf{P C V}=$ packed cell volume, $\mathbf{R B C}=$ Red Blood Cell.

\subsection{The difference in WBC and WBC differentiation between the four study groups.}

This study indicates the significant difference in mean of WBC, Lymphocytes, Monocytes and granulocytes of the study, where the mean of WBC and Lymphocytes were significantly lower in HD patients without diabetes group and HD patients with diabetes group $(6.7 \pm 0.53$ and $6.8 \pm 0.65) \times 10^{9} \backslash \mathrm{L}$ and $(31.47 \pm 4.59$ and $30.23 \pm 5.84) \%$ respectively, compared with control $(7.14 \pm 1.37) \times 10^{9} / \mathrm{L}$ and $(35.76 \pm 4.21) \%$. While there were no significant differences in mean Lymphocytes between HD patients with a diabetes group and HD patients without a diabetes group. Also, the level of WBC and Lymphocytes showed a significant decrease in diabetic patients $(7.12 \pm 0.59) \times 10^{9} / \mathrm{L}$ and $(32.34 \pm 3.02) \%$ when compared with control. The mean of Mono \% was significantly higher in HD patients with diabetes and HD patients without diabetes (17.23 \pm 7.28 and $16.61 \pm 9.17) \%$ respectively followed by in diabetic patients $(11.17 \pm 1.45) \%$ compared with control $(11.16 \pm 1.53) \%$. Whereas mean of Granulocyte\% was significantly higher in HD patients with diabetes (59.31 \pm 9.45$) \%$, while no significant difference among diabetic patients, control group and HD patients without diabetes group in mean granulocyte \% were $(52.71 \pm 4.18$, $53.19 \pm 4.16$ and $53.21 \pm 14.16) \%$ respectively, as shown in the table (6).

\section{Discussion:}

\subsection{Determination of Chemrein between the four study groups}

The results in (Table 2) agreed with (Salama et al., 2016) who showed a significant difference in levels of chemerin in HD patients $(332.1 \pm 21.54) \mathrm{ng} / \mathrm{ml}$ compared to healthy $(278.6 \pm 10.02) \mathrm{ng} / \mathrm{ml}$, and who found that the chemerin level increased in HD patients with diabetes (354.1 \pm 1.4$) \mathrm{ng} / \mathrm{ml}$ compared with HD patients without diabetes $(329 \pm 19.9) \mathrm{ng} / \mathrm{ml}$.
Table (6): The difference in WBC, Lympho\%, Mono\% and Granulocyte\% between the four study groups.

\begin{tabular}{llllll}
\hline Groups & $\mathrm{N}$ & $\begin{array}{l}\text { Mean } \pm \text { SD } \\
\text { WBC } \\
(4-10) \times 10^{9} / \mathrm{L}\end{array}$ & $\begin{array}{l}\text { Mean } \pm \text { SD } \\
(20-40) \%\end{array}$ & $\begin{array}{l}\text { Mean } \pm \text { SD } \\
\text { Mono. \% } \\
(3-15)\end{array}$ & $\begin{array}{l}\text { Mean } \pm \text { SD } \\
\text { Granulocyte\% } \\
(50-70)\end{array}$ \\
\hline Control & 25 & $7.14 \pm 1.37^{\mathrm{a}}$ & $35.76 \pm 4.21^{\mathrm{a}}$ & $11.16 \pm 1.53^{\mathrm{a}}$ & $53.19 \pm 4.16^{\mathrm{a}}$ \\
Diabetes & 25 & $7.12 \pm 0.59^{\mathrm{a}}$ & $32.34 \pm 3.02^{\mathrm{b}}$ & $11.17 \pm 1.45^{\mathrm{a}}$ & $52.71 \pm 4.18^{\mathrm{a}}$ \\
$\begin{array}{l}\text { HD } \\
\text { patients }\end{array}$ & 35 & $6.8 \pm 0.65^{\mathrm{b}}$ & $31.47 \pm 4.59^{\mathrm{b}}$ & $17.23 \pm 7.28^{\mathrm{b}}$ & $59.31 \pm 9.45^{\mathrm{b}}$ \\
$\begin{array}{l}\text { with } \\
\text { diabetes }\end{array}$ & & & & & \\
$\begin{array}{l}\text { HD } \\
\text { patients } \\
\text { without }\end{array}$ & 35 & $6.7 \pm 0.53^{\mathrm{b}}$ & $30.23 \pm 5.84^{\mathrm{b}}$ & $16.61 \pm 9.17^{\mathrm{b}}$ & $53.21 \pm 14.16^{\mathrm{a}}$ \\
diabetes & & & & & \\
$\begin{array}{l}\text { Total } \\
\text { P Value }\end{array}$ & 120 & $6.22 \pm 2.02$ & $32.02 \pm 8.82$ & $14.52 \pm 6.95$ & $54.88 \pm 9.90$ \\
\end{tabular}

*Different Letters (a, b, c): Mean significant difference at $\mathrm{P} \leq 0.05$.

\section{SD=Stander Deviation, $\mathbf{W B C}=$ White Blood Cell, Lympho=}

Lymphocyte, Mono= Monocyte.

These results were consistent with (Ali and Al Hadidi, 2013, Coimbra et al., 2014, Ahmed and Tahir, 2015) who recorded that the chemerin level significant increase in T2DM patients compared with control. These results were inconsistent with (Alissa et al., 2016) who recorded that the chemerin level non-significantly increased in control compared with diabetic patients. In this study, chemerin level increased in diabetic patients compared with control, and this may be due to taking anti-diabetic drugs by a proportion of their T2DM study subjects(Ali and $\mathrm{Al}$ Hadidi, 2013).

This adipokine is known to act on glucose metabolism in the liver, skeletal muscle and adipose tissue, promoting regulation of glucose absorption and modulating insulin secretion and sensitivity(Fontes et al., 2018). These results showed that the chemerin level increased in HD patients compared with control may due to decrease of renal function, which has a significant impact on serum chemerin concentration(Salama et al., 2016). The increased circulating chemerin concentration observed in HD patients is not a consequence of the adipose tissue excess, and there is no reason to assume that these medications relevantly impacted the presented results, as mentioned (Mathew and Corso, 2009, Salama et al., 2016). While circulating chemerin level is closely related to renal function, its high serum concentration found in CKD patients is probably a result of a renal failureassociated with decrease of GFR rate and impaired chemerin urine excretion(Blaszak et al., 2015). Chemerin is predictive of renal impairment and patients with high chemerin levels are at a significantly higher CVD risk, independent from their renal function. From a clinical point of view, the treatment of excessive chemerin levels to prevent the onset of diabetes or renal diseases might be a future task to be addressed by researchers (Leiherer et al., 2016). 


\subsection{Human IL-18(Interleukin 18) level between the four study groups}

The results in (Table 3)agreed with (Shi et al.,2012, Abid Hammed,2019) who recorded that the mean IL-18 was significantly higher among HD patients with diabetes and diabetic patients compared to control. Patients with T2DM recently diagnosed appeared to have an essentially higher IL-18 level in contrast with non-diabetic subjects(Aso et al., 2003). IL-18 levels were raised by acute hyperglycemia in humans through an oxidative mechanism(Abid Hammed,2019). The increased IL-18 in $\mathrm{HD}$ patients is due to many reasons: firstly, CKD diagnosis, which is responsible for decreased renal clearances of IL-18, was probably the major sites of cytokine elimination, the primary factor that could affect these results. IL-18 is a mid-molecule and protein-bound uremic toxin which is difficult to extract by any of the currently available dialytic strategies(Vanholder et al., 2008), hence the reported IL-18 accumulation in HD patients. Secondly, activating the monocyte and macrophage network discovered during dialysis session produces multiple inflammatory cytokines, which may also demonstrate the serum's increase in IL18(Formanowicz et al., 2015). Thirdly, serum IL-18 is a marker of tubulo-interstitial kidney tissue lesion, so level of serum IL-18 directly correlated with necrotic and dystrophic changes in epithelial tubules and interstitial fibrosis in kidney of HD patient (Kraydaschenko et al., 2016). This study found that the elevated serum IL-18 levels in diabetic patients may result from kidney tissue from DN patients. IL-18 is increasingly secreted from tubular cells through acute ischemic kidney failure. It is mainly expressed in tubular kidney epithelium so that IL18 levels of tubular cells may also be increased in diabetes cases and that the cytokine expect an unsafe activity in DN.

\subsection{Human high sensitivity C-Reactive Protein (hs- $C R P$ ) level in four study groups}

The findings in (Table 4) were symmetrical with (Shelbaya et al.,2012, Lachine et al., 2016) who recorded that the hsCRP levels were increased in the diabetic patients and decreased in the control group, with statistically significant difference between them $(\mathrm{p}<0.05)$. And these findings were symmetrical with (Abd Rabo et al., 2016, Salama et al., 2016, Leiherer et al., 2016) who recorded that the mean of hsCRP levels was increased in HD patients compared with control group. These results were unsymmetrical with (Shi et al., 2012) who found that the mean of hs-CRP was decreased in HD patients. This study showed that the inflammatory marker in HD patients is the presence of proinflammatory state as evidenced by significant increase in hsCRP concentration caused by a synergism of different mechanisms, such as malnutrition, oxidative stress, genetic factors and chronic inflammation(Panichi et al., 2001); in addition, underlying etiology of CKD, such as diabetes or hypertension is by itself a major contributory factor to the existing inflammation(Amanullah et al., 2010; Gowda et al., 2015). Alterations in the immune system in CKD by uremia are associated with a state of immune dysfunction characterized by immune-depression that contributes to the high prevalence of infections among HD patients(Lagrand et al., 1999). Furthermore, vascular calcification in more advanced CKD stage may be another explanation for higher hs-CRP levels(Panichi et al., 2001). Also, this study recorded an increase of mean hs-CRP levels in T2DM patients compared with control, because a possible mechanism by which T2DM patients might induce inflammation by increasing advanced glycation end products that may activate macrophages and increase oxidative stress and IL-6 synthesis, leading to the high production of hsCRP, these results suggest a concomitant action of T2DM in the occurrence of an increase in the inflammatory process that is reflected by an increase in hsCRP levels (Lima et al., 2007).

Correlation coefficient between Chemerin with hs-CRP and Chemerin with IL-18:

These results agreed with (Alissa et al., 2016, Lachine et al.,2016) who recorded positive correlation between levels of chemerin and hs-CRP among T2DM patients compared with control. And these results agreed with (Blaszak et al., 2015) who showed a significant positive correlation between concentration of chemerin and CRP in HD patients compared to the control. These results disagreed with (Shukla et al.,2016) who found no difference in the concentrations of IL-18 in HD patients compared to the control group. The presence of sustained inflammation in adipose tissue is an initial signal for increased chemerin formation and production, and adipose tissue regulates the ratio of active to total chemerin acting within adipose tissue thus affecting the inflammatory functions induced by immune cells recruitment(Lachine et al., 2016). The elevated chemerin levels in HD patients correlated with adipose tissue infiltration by macrophages and production of well-established inflammatory mediators such as CRP, IL 18, and tumor necrosis factoralpha (TNF- $\alpha$ ) (Salama et al., 2016).

These results showed that chemerin level was positively correlated to the IL-18 and hs-CRP in study groups, which are considered inflammatory markers. This may be explained because chemerin has a dual nature as an adipokine and a chemokine (Fontes et al., 2018). Chemerin showed positive correlation with markers of inflammation in previous study (Lehrke et al., 2009) and the positive association between baseline chemerin and hs-CRP here suggests that serum chemerin is associated with inflammation in T2DM patients and indicating a relationship mainly with systemic inflammation (Kim et al., 2014). In this study, there is a positive correlation between chemerin concentration levels and hs-CRP index in HD patients. This fact suggests a key role of the ChemR23/ chemerin axis in directing plasmacytoid dendritic cell trafficking, which can play a significant role in regulating the immune response by enhancing chemoattraction of the cells of the immune response toward sites of pathological inflammation(Abd Rabo et al., 2016). HsCRP is a sensitive marker of tissue damage, inflammation and infection reflecting the degree of underlying inflammatory response and being a beneficial measure of immune injury to tissues (Formanowicz et al., 2015). Hyperglycemia actuate inflammatory mediators, for example, IL-18 in kidney tissue, and since IL-18 receptors are present mainly in proximal renal tubules and increment with renal tissue damage, so the microalbuminuria will increment as long as serum IL-18 increment. IL-18 can be considered as great indicators for $\mathrm{DN}$; consequently it could be recommended that IL-18 is considered as a 
predictive factor for checking the early $\mathrm{DN}$ and, furthermore, the likelihood of having a therapeutic methodology impact on DN improvement(Abid Hammed, 2019). Therefore, serum IL-18 levels present in T2DM as result of the predominant viscous deposition of lipids related with the disorder. IL-18 levels were gradually increased in DN to reach the highest level in the microalbumin phase.

\subsection{The difference in $\mathrm{Hb}, \mathrm{PCV}, \mathrm{RBC}, \mathrm{WBC}$ and $\mathrm{WBC}$ type in the four study groups.}

The results in Tables (5 and 6) agreed with results by Abd Rabo et al (2016) who found that significantly decreased of CBC indices in HD patients compared with control. These results agreed with (Shukla et al., 2016) who recorded that no significant in $\mathrm{Hb}, \mathrm{PCV}, \mathrm{RBC}$ and WBCs between T2DM patients and control. These results disagreed with (George et al., 2015, Iyawe and Adejumo, 2018) who recorded increased of WBCs in HD patients compared with control. Hematological investigations, especially full blood counts, are good indicators in health and disease states, helping to understand the real disease presentation juxtaposed to the clinical features in the patients(George et al., 2015). This study showed decrease in $\mathrm{Hb}, \mathrm{PCV}$ and $\mathrm{RBC}$ in $\mathrm{HD}$ patients compared with diabetic patients and control; this decrease is due to hematuria and gastrointestinal blood loss or due to a decrease in the production of erythropoietin by the kidney, leading to decreased production of RBC in the bone marrow, and anemia that causes hypoxia; Hypoxia will increase hepsidin that causes functional iron deficiency through inhibition of iron absorption in the intestine and inhibition of Fe distribution in blood circulation as more is stored in macrophages or spleen(Abd Rabo et al.,2016, Thaha et al., 2018).

Kidney function decline will result in a decline in EPO production and, as a consequence, result in decreased $\mathrm{Hb}$ synthesis, leading to a fall in total RBC count; clotting of blood during dialysis is also responsible for low Hb level in CKD patients(Kutuby et al., 2015). Uremia interferes with erythropoiesis, granulocyte and immune functions. As a result, uremic patients are almost invariably anemic, and have a high incidence of infections and hemorrhagic complications(George et al., 2015). This study showed decreased WBC count in HD patients. The possible mechanism in which CKD leads to a slight decrease in total leukocyte count may be explained by complement activation in vivo due to exposure of blood to artificial dialyzer membranes in patients undergoing dialysis. The complement is typically C3a or C5a, produced by the classic complement activation pathway. Complement activation induces neutrophil aggregation and adherence to endothelial surface with resultant fall in total leukocyte count. In patients undergoing hemodialysis, the incidence of this affect may be as high as 20\% (Latiweshob et al., 2017, Iyawe and Adejumo, 2018). This study showed that CKD was associated with higher monocyte and lower lymphocyte counts; both of which are independently associated with the promotion of cardiovascular outcomes(George et al., 2018). Granulocyte is associated with rapid progression to ESRD, cardiovascular morbidity, and mortality. This may, therefore, imply that our patients with CKD are at increased risk of developing CVD; hence, there is a need for aggressive CVD factor modification and treatment (Jabbar et al., 2015, Iyawe and Adejumo, 2018). Also, this study show that non-significant decreased of $\mathrm{Hb}, \mathrm{PCV}$ and RBCs in diabetic patients group and control group, where chronic inflammatory state in DM due to insulin action on the adipose tissue, muscles and liver promote differentiation and maturation of WBC via proinflammatory cytokines. Possible mechanisms for decreased RBC indices in T2DM are structural modifications of erythrocytes membrane, changes of surface electric charge, erythrocyte aggregation, that could lead to the shorter lifespan of RBC(Milosevic and Panin, 2019).

\section{Conclusion}

The higher levels of hs-CRP, chemerin and IL-18 in HD patients than control are a circulating inflammatory marker. This finding suggests that patients with two associated diseases have a more active inflammatory state. While raised hs-CRP, chemerin and, IL-18 in diabetic patients are prone to increase the future relative risk of cardiovascular events and other complications. Hence raised these markers indicates the role of ongoing inflammation in the management of diabetes. This study appeared that HD Patients have abnormal hematological parameters. It has been suggested that in CKD, weaken production of EPO is the major reason for the reduction in RBC count, Hb concentration, PCV and, WBC.

\section{Declaration of Competing Interests}

None

\section{Acknowledgements}

Our special thanks go to all the staff of the industrial renal department, diabetes center, department of Chemistry Laboratory and Blood Laboratory at Ramadi General Hospital for helping us in the collection and analysis of the samples. Our profound thanks go to all patients and healthy people who accepted to participate in the study.

\section{References}

Abd Rabo SA, Mohamed NA, Tawfik NA and Hamed MM. 2016. Serum chemerin level in chronic kidney disease. Egypt $J$ Intern Med., 28(3):99.

Abid Hammed SM. 2019. Study of Relationship between Several Interleukins and Some Biochemical Parameters in Type II Diabetics Patients. Ph. Thesis. College of Science, University of Anbar.

Ahmed HS and Tahir NT. 2015. Chemerin as a New Marker in Iraqi Newly Diagnosed Type 2 Diabetes Mellitus. AJPS., 15(1):613.

Ali TM and Al Hadidi K. 2013. Chemerin is associated with markers of inflammation and predictors of atherosclerosis in Saudi subjects with metabolic syndrome and type 2 diabetes mellitus. BJBAS., 2(2):86-95.

Ali Z, Ridha MR and Bahar E. 2019. Serum C-Reactive Protein in chronic kidney disease patients undergoing hemodialysis and correlation with dialytic age. In J Phy: Conference Series., 1246 (1). IOP Publishing. 
Alissa EM, Helmi SR, Alama NA and Ferns GA. 2016. Serum Chemerin and Cardiovascular Risk Factors in Diabetic Subjects without Established Vascular Disease. J Adv Med Medical Res., 17.

Amanullah S, Jarari A and Govindan M. 2010. Association of hsCRP with diabetic and non-diabetic individuals. Jordan J Biol Sci. 147(612):1-1.

Aso Y, Okumura KI, Takebayashi K, Wakabayashi S and Inukai T. 2003. Relationships of plasma interleukin-18 concentrations to hyperhomocysteinemia and carotid intimal-media wall thickness in patients with type 2 diabetes. Diabetes care., 26(9):2622-7.

Blaszak J, Szolkiewicz M, Sucajtys-Szulc E, Konarzewski M, Lizakowski S, Swierczynski J and Rutkowski B. 2015. High serum chemerin level in CKD patients is related to kidney function, but not to its adipose tissue overproduction. Renal failure., 37(6):1033-8.

Chang CH, Fan PC, Lin CY, Yang CH, Chen YT, Chang SW, Yang HY, Jenq CC, Hung CC, Yang CW and Chen YC. 2015. Elevation of interleukin-18 correlates with cardiovascular, cerebrovascular, and peripheral vascular events: a cohort study of hemodialysis patients. Medicine., 94(42).

Coimbra S, Brandão Proença J, Santos-Silva A and Neuparth MJ. 2014. Adiponectin, leptin, and chemerin in elderly patients with type 2 diabetes mellitus: a close linkage with obesity and length of the disease. BioMed research international.

Donate-Correa J, Martín-Núñez E, Muros-de-Fuentes M, MoraFernández C and Navarro-González JF. 2015. Inflammatory cytokines in diabetic nephropathy. JDR.

Fischer CP, Perstrup LB, Berntsen A, Eskildsen P and Pedersen BK. 2005. Elevated plasma interleukin-18 is a marker of insulinresistance in type 2 diabetic and non-diabetic humans. Clin. Immunol., 117(2):152-60.

Fontes VS, Neves FS and Cândido AP. 2018. Chemerin and factors related to cardiovascular risk in children and adolescents: a systematic review. Rev. Paul. Pediatr., 36(2):221-9.

Formanowicz D, Wanic-Kossowska M, Pawliczak E, Radom M and Formanowicz P. 2015. Usefulness of serum interleukin-18 in predicting cardiovascular mortality in patients with chronic kidney disease-systems and clinical approach. Sci Rep., 5:18332.

Franz MJ, Bantle JP, Beebe CA, Brunzell JD and Chiasson JL. 2012. Evidence-based nutrition principles and recommendations for the treatment and prevention of diabetes and related complications. Diabetes Care, 26: 51-61.

George C, Matsha TE, Erasmus RT and Kengne AP. 2018. Haematological profile of chronic kidney disease in a mixedancestry South African population: a cross-sectional study. BMJ open., 8(11).

George SV, Pullockara JK, Kumar SS and Mukkadan JK. 2015. A study to assess changes in the hematological profile in chronic kidney disease. TPI., 4(6, Part A):1.

Gowda BH, Meera KS and Mahesh E. 2015. Serum levels of high sensitivity $C$ reactive protein and malondialdehyde in chronic kidney disease. IJMRHS., 4(3):608-615.

Haddad NI, Nori E and Hamza SA. 2018. Correlations of Serum Chemerin and Visfatin with other Biochemical Parameters in Iraqi Individuals with Metabolic Syndrome and Type Two Diabetes Mellitus. Jordan J Biol Sci, 11(4):4369.

Iyawe IO andAdejumo OA. 2018. Hematological profile of predialysis chronic kidney disease patients in a tertiary hospital in Southern Nigeria. J Med Trop., 20(1):36.
Kim SH, Lee SH, Ahn KY, Lee DH, Suh YJ, Cho SG, Choi YJ, Lee DH, Lee SY, Hong SB and Kim YS. 2014. Effect of lifestyle modification on serum chemerin concentration and its association with insulin sensitivity in overweight and obese adults with type 2 diabetes. Clin Endocrinol., 80(6):825-33.

Kraydaschenko O, Berezin A, Dolinnaya M and Swintozelsky A. 2016. Serum Interleukin-18 as a Biomarker of Tubular Kidney Damage in Patients with Chronic Glomerulonephritis. Biol Markers Guid Ther., 3(1):185-91.

Kuo IC, Lin HY, Niu SW, Lee JJ, Chiu YW, Hung CC, Hwang SJ and Chen HC. 2018. Anemia modifies the prognostic value of glycated hemoglobin in patients with diabetic chronic kidney disease. PloS one., 13(6):e0199378.

Kurts C, Panzer U, Anders HJ and Rees AJ. 2013. The immune system and kidney disease: basic concepts and clinical implications. Nat. Rev. Immunol., 13: 738-753.

Kutuby F, Wang S, Desai C and Lerma EV. 2015. Anemia of chronic kidney disease. Dis Mon: DM., 61(10):421.

Lachine N, ElSewy FZ, Megallaa MH, Sadaka M, Khalil G, Rohoma K and Amin NG. 2016. Association between serum chemerin level and severity of coronary artery disease in Egyptian patients with type 2 diabetes. J Diabetol., 2:3.

Lagrand WK, Visser CA, Hermens WT, Niessen HW, Verheugt FW, Wolbink GJ and Hack CE. 1999. C-reactive protein as a cardiovascular risk factor: more than an epiphenomenon. Circul., 100(1):96-102.

Latiweshob OB, Elwerfaly HH and Sheriff DS.2017. Haematological changes in predialyzed and hemodialyzed chronic kidney disease patients in libya. IOSR J Dent Med Sci., 16:106112.

Lehrke M, Becker A, Greif M, Stark R, Laubender RP, von Ziegler F, Lebherz C, Tittus J, Reiser M, Becker C and Goke B. 2009. Chemerin is associated with markers of inflammation and components of the metabolic syndrome but does not predict coronary atherosclerosis. Eur J Endocrinol., 161(2):339.

Leiherer A, Muendlein A, Kinz E, Vonbank A, Rein P, Fraunberger P, Malin C, Saely CH and Drexel H. 2016. High plasma chemerin is associated with renal dysfunction and predictive for cardiovascular events-Insights from phenotype and genotype characterization. Vascul pharmacol., 77: 60-68.

Lima LM, Carvalho MD, Soares AL, Sabino AD, Fernandes AP, Novelli BA and Sousa MO. 2007. High-sensitivity C-reactive protein in subjects with type 2 diabetes mellitus and/or high blood pressure. Arq Bras Endocrinol Met., 51(6):956-9560.

Mathew T and Corso O. 2009. Early detection of chronic kidney disease in Australia: which way to go. Nephrol., 14(4): 367-373.

Milosevic D and Panin VL. 2019. Relationship between hematological parameters and glycemic control in type 2 diabetes mellitus patients. J Med Biochem., 38(2):164-71.

Panichi V, Migliori M, De Pietro S, Taccola D, Bianchi AM, Norpoth M, Metelli MR, Giovannini L, Tetta C and Palla R. 2001. $\mathrm{C}$ reactive protein in patients with chronic renal diseases. Ren. Fail., 23(3-4):551-62.

Pfützner A, Schöndorf T, Hanefeld M and Forst T. 2010. Highsensitivity C-reactive protein predicts cardiovascular risk in diabetic and nondiabetic patients: effects of insulin-sensitizing treatment with pioglitazone. J Diabetes sci technol., 4(3):706-16.

Salama FE, Anass QA, Abdelrahman AA and Saeed EB. 2016. Chemerin: A biomarker for cardiovascular disease in diabetic chronic kidney disease patients. Saudi J Kidney Dis Transpl., 27(5):977. 
Shelbaya S, Amer H, Seddik S, Allah AA, Sabry IM, Mohamed T and El Mosely M. 2012. Study of the role of interleukin-6 and highly sensitive C-reactive protein in diabetic nephropathy in type 1 diabetic patients. Eur. Rev. Med. Pharmacol. Sci., 16(2):176182.

Shi B, Ni Z, Cao L, Zhou M, Mou S, Wang Q, Zhang M, Fang W, Yan Y and Qian J. 2012. Serum IL-18 is closely associated with renal tubulointerstitial injury and predicts renal prognosis in IgA nephropathy. Med Inflam., 2012.

Shukla DK, Chandra KP and Pawah AK. 2016. Study of hematological indices in patients with diabetes mellitus and hypertensive diabetes mellitus. Indian J Med Res., 1(4):28-31.

Stanifer JW, Jing B, Tolan S, Helmke N, Mukerjee R, Naicker S, Patel U. 2014. The epidemiology of chronic kidney disease in sub-Saharan Africa: a systematic review and meta-analysis. Lancet Glob Health, 2(3):e174-81.
Thaha M, Imroati TA, Widodo S and Pranawa S. 2018. Comparison of High-sensitivity C-reactive Protein Level between Chronic Kidney Disease Stages. Bio Heal Sci J., 1(1):1-9.

Vanholder R, Fouque D, Glorieux G, Heine GH, Kanbay M, Mallamaci F, Massy ZA, Ortiz A, Rossignol P, Wiecek A and Zoccali C. 2016. Clinical management of the uraemic syndrome in chronic kidney disease. Lancet Diabetes Endocrinol., 4(4):3603673.

Vanholder R, Van Laecke S and Glorieux G. 2008. What is new in uremic toxicity?. Pediatric nephrol., 23(8):1211-1221. 